\title{
Antibacterial activity of zinc oxide nanoparticles obtained by pulsed laser ablation in water and air
}

\author{
Daria Goncharova ${ }^{1 *}$, Ekaterina Gavrilenko ${ }^{1}$, Anna Nemoykina $^{2}$, and Valery Svetlichnyi ${ }^{1}$ \\ ${ }^{1}$ Tomsk State University, Laboratory of Advanced Materials and Technology, 634050 Tomsk, Russia \\ ${ }^{2}$ Tomsk State University, Laboratory of Biopolymers and Biotechnology, 634050 Tomsk, Russia
}

\begin{abstract}
The paper studies physicochemical and antibacterial properties of $\mathrm{ZnO}$ nanoparticles obtained by pulsed laser ablation in water and air. Their composition and structure were studied by X-ray diffraction, transmission and scanning electron microscopy. Antibacterial activity of the nanoparticles was examined by its affection on Gram-positive Staphylococcus aureus (S.aureus). The dependence of nanoparticles' physical and chemical antibacterial properties on the conditions of the ablation was shown. The model materials for the antibacterial bandage were made of cotton, filter paper and biodegradable polymer scaffolds (poly-l-lactide acid), and then they were coated with the obtained $\mathrm{ZnO}$ nanoparticles. The model bandage materials were examined by the scanning electron microscopy method and their antibacterial activity (ISO 20743:2013) was determined. High activity of all the samples against S.aureus was proved.
\end{abstract}

\section{Introduction}

One of the problems of modern medicine is the fight against antibiotic-resistant bacterial strains. Staphylococci, Streptococci, Escherichia coli (E.coli), Gonococcus, Pneumococcus, Pseudomonas aeruginosa and other bacteria cause pyo-inflammatory diseases of various kinds and locations. For example, S.aureus is the main causative agent of purulent surgical infections. The widespread use of antibiotics leads to an increase in bacterial mutations and resistance. As a result, the resistance to S.aureus is observed among $70 \%$ of patients with purulent infection, because their microflora is resistant to penicillin, streptomycin, chlortetracycline, laevomycetin and erythromycin. [1]. That is why it's necessary to develop new generations of antibiotics and other agents to suppress bacterial infections. In this case nanotechnology can support medical industry. There is an urgent problem connected with the creation of nonremovable bandage based on biodegradable polymers $[2,3]$ with prolonged antibacterial action for the treatment and prevention of purulent infections of wounds of various origins, especially in the field conditions.

There has been a rapid development of nanotechnology in recent decades. This has led to the development and implementation of nanomaterials as therapeutic agents necessary for the treatment of a number of diseases, tissue repair, drug delivery, and the creation of fast and ultra-sensitive diagnostic tools. Nanoparticles (NPs) are attractive as promising antibacterial agents [4-6]. A number of inorganic nanostructures such as silver, copper, zinc, etc. exhibit antibacterial properties [7-9]. Thus, zinc oxide nanoparticles have good antimicrobial and antifungal properties. They are potentially applicated in preserving food products [10], making medicines, and orthopedic ceramic implants [11] and as materials for wound dressings. $\mathrm{ZnO}$ turned out to be low-toxic for human cells and have good biocompatibility [12]. In addition, zinc is an important element of human physiological activity. However, the effectiveness and mechanisms of impact, selectivity and reliability of nanoparticles, including $\mathrm{ZnO}$, have not been fully studied.

There are many physical and chemical methods for obtaining nanoscale zinc oxide $[13,14]$. At the present time, the pulsed laser ablation method (PLA) is being intensively developed. This method allows obtaining "pure" and highly active nanostructures for biomedical applications [15]. In this way, femto- and nanosecond lasers are used to obtain $\mathrm{ZnO}$ NPs trough PLA in liquid for antibacterial applications $[15,16]$. It should be noted that the PLA in the liquid for the synthesis of NPs is used more often than the PLA in the gas. Previously we have already investigated antibacterial properties of justprepared suspension of $\mathrm{ZnO}$ on the textile [17].

The purpose of this paper is to present the results of study of the physicochemical and antibacterial properties of $\mathrm{ZnO}$ nanopowders obtained by the $\mathrm{Zn}$ PLA target in water and air. The modeled material for antibacterial bandage consisted of $\mathrm{ZnO}$ nanoparticles and cotton, paper and biodegradable polymer. Antibacterial properties of the resulting materials were investigated.

\footnotetext{
Corresponding author: $\underline{\mathrm{dg} \text { va@ } @ \text { list.ru }}$
} 


\section{Experimental}

\subsection{Sample preparation}

NPs were obtained of $\mathrm{Zn}$ by the PLA method in liquid medium (distilled water) and in gas phase (air). The reactors schemes are shown in Figure 1. Irradiation (1) of Nd:YAG laser (1064 nm, $4 \mathrm{~ns}, 150 \mathrm{~mJ}, 20 \mathrm{~Hz})$ is focused on the surface of the zinc (purity 99.9\%) target (2), which was placed in a glass container (3) filled with a solvent $\left(\mathrm{H}_{2} \mathrm{O}\right)$ or gas (air). PLA in air atmosphere was carried out in a cylindrical reactor, which is shown in the bottom of Figure 1. PLA in the liquid was performed in heat resistant glass filled with distilled water without additional external heating. The cylindrical reactor and target holder were automatically moved in the XY plane orthogonaly to the pump beam to scan the target's surface uniformly to avoid the formation of large craters. Nanopowders obtained in air were mechanically removed from the walls. The dispersion prepared in water (with concentration of about $1 \mathrm{~g} / \mathrm{L}$ ) was bubbled by air and dried at $60{ }^{\circ} \mathrm{C}$ until the formation of nanopowder. The obtained samples were named as $\mathrm{Zn} \_$Air and $\mathrm{Zn} \mathrm{H}_{2} \mathrm{O}$ (where Air and $\mathrm{H}_{2} \mathrm{O}$ are the medium they were obtained in).

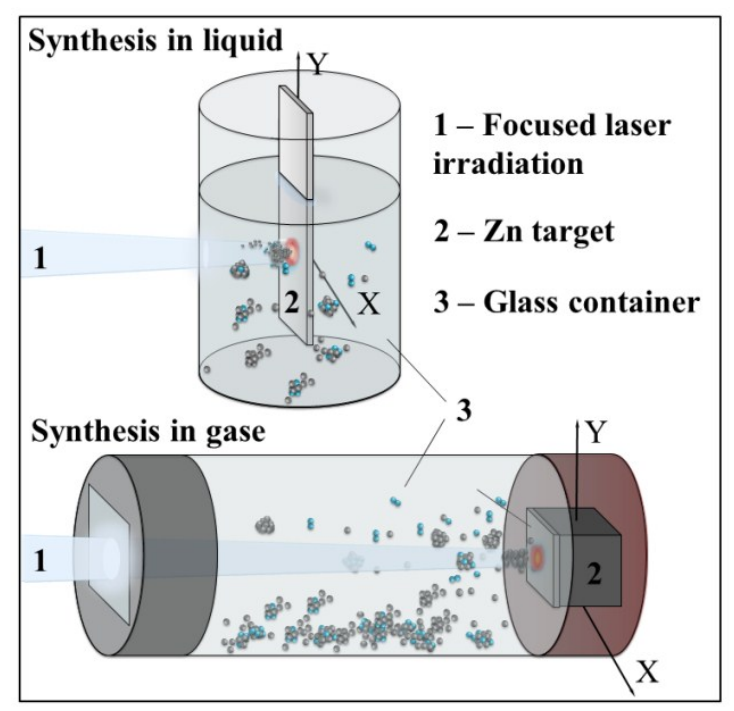

Fig. 1. Experimental setup of PLA process: in water (in the top) and air (below).

In order to model bandages with antibacterial properties, we used obtained NPs and cotton manufactured by "TexLine" ("Textilnaya Liniya", Ivanovo, Russia, density $120 \mathrm{~g} / \mathrm{cm}^{2}$ ), filter paper ("Melior XXI", Moscow, Russia, density $97 \mathrm{mg} / \mathrm{cm}^{2}$ ) and biodegradable scaffolds from poly-l-lactide acid (PLLA) polymer (density of $20 \mathrm{~g} / \mathrm{m}^{2}$ ). The PLLA scaffolds were produced by electrospinning method [18]. They were kindly provided by S. Tverdokhlebov and E. Bolbasov (Tomsk Polytechnic University).

Initially, $200 \mathrm{mg}$ of the nanopowder was dispersed in $100 \mathrm{ml}$ of water with the help of ultrasonic bath $(50 \mathrm{~W}$, $35 \mathrm{kHz}$, "OOO "Sapphire", Moscow, Russia). Pieces of materials $10 \mathrm{~cm} \times 20 \mathrm{~cm}\left(200 \mathrm{~cm}^{2}\right)$ were placed on a fiberglass mesh. Sorption capacities were estimated. The following results were obtained: $16 \mu \mathrm{l} / \mathrm{cm}^{2}$ for cotton and paper and $25 \mu \mathrm{l} / \mathrm{cm}^{2}$ for PLLA. $3 \mathrm{ml}$ of the prepared dispersion was applied to the textile surface by pipette until it was absorbed completely. Then, the substrates were placed on the mesh and dried by blowing with the temperature of $20^{\circ} \mathrm{C}$. The procedure was repeated a lot of times until the dispersion was completed. The equal amount of the dispersion was applied to the material on each side. Thus, the average particles' concentration in the samples was $1 \mathrm{~g} / \mathrm{l}$. We suppose that this technique excludes losses of mass.

\subsection{Characterization methods}

\subsubsection{Sample characterization}

The crystal structure was determined by powder diffraction by X-ray diffractometer (XRD-6000, Shimadzu, Japan) with CuK $\alpha$ radiation $(\lambda=1.54056 \AA)$ in the $2 \theta$ ranging from $10^{\circ}$ to $70^{\circ}$. Phase identification and the quantitative analysis of the diffractograms were conducted with the help of the database of powder diffraction patterns (PDF4) and PowderCell 2.4 software (BAM, Germany) respectively. Transmission electron microscopy was used to analyze the morphology and particles size by (CM12 Philips, Netherlands) microscope. The samples were dispersed in ethanol and deposited on the carbon-copper grids. The topology of the surface of the nanocomposite fibres was studied through scanning electron microscope (VEGA $3 \mathrm{SBH}$, Tescan, Czech Republic) without additional sample treatment.

\subsubsection{Antibacterial activity experiments}

S.aureus was used to study antibacterial activity (test strain ATCC 25923). This strain was chosen as one of the most common pathogens.

Antibacterial activity of the nanoparticle powder was tested by quality serial dilution method. This method is qualitative. It is based on direct determination of minimal bactericidal concentration (MBC) of NPs in solution. $\mathrm{MBC}$ is the minimal concentration of an antiseptic agent causing the complete death of the bacterium under standard experimental conditions.

The work solution of test strains was prepared from twenty-four-hours cultures grown on meat-peptide agar (MPA) at $37{ }^{\circ} \mathrm{C}$ for 24 hours. The culture was washed with the sterile saline solution of sodium chloride by adjusting the optical density to 10 units $\left(10^{9} \mathrm{CFU} / \mathrm{ml}\right)$. Then, it was diluted to the number $10^{6} \mathrm{CFU} / \mathrm{ml}$.

Matrix solutions of the nanoparticles were prepared at a concentration of $10 \mathrm{~g} / \mathrm{l}$ in physiological saline. Then, the matrix solutions were diluted consecutively 10 times to the minimal concentration of $0.001 \mathrm{~g} / \mathrm{l}$. Thus, 5 solutions of nanoparticles with different concentrations were obtained.

$9 \mathrm{ml}$ of NPs' dispersions and $1 \mathrm{ml}$ of bacterial culture were mixed in the tubes. The final concentration of the 
microorganisms in each tube was $10^{5} \mathrm{CFU} / \mathrm{ml}$. The tubes were closed by sterile metal caps and incubated in a thermostat with the shaker at $100 \mathrm{rpm}$, at $37^{\circ} \mathrm{C}$ for 24 hours. After incubation, $100 \mu$ of the dispersion from the tubes were plated on MPA in Petri dishes and cultured at $37{ }^{\circ} \mathrm{C}$ for 24 hours. The bacteria were examined for the presence or absence of growth.

Antibacterial activity of model bandages was investigated equivalently to the method ISO 20743:2013 [19]. Filter paper, polymer modified with nanoparticles and pure (control) cotton were cut into test objects in the size of $3 \times 5 \mathrm{~cm} .0 .2 \mathrm{ml}$ of an 18-hour suspension of bacterial culture at the concentration of $10^{5} \mathrm{CFU} / \mathrm{ml}$ in physiological saline was applied to each slice. Test objects were washed for 5 minutes in $20 \mathrm{ml}$ of physiological saline after the contact lasting for 0 and 24 hours. Serial dilutions were made. $100 \mu \mathrm{l}$ of wash liquid was poured of MPA in Petri dishes and cultured at $37{ }^{\circ} \mathrm{C}$ for 24 hours. The amount of grown microorganisms was counted in the inoculations from antimicrobial and control samples, after cultivation. Further, the death percentage of test microorganisms was determined.

The value of antibacterial activity $A$ was determined according to the formula:

$A=\left(\lg C_{t}-\lg C_{0}\right)-\left(\lg T_{t}-\operatorname{Ig} T_{0}\right)=F-G$

where $A$ is the importance of antibacterial activity:

$F$ is the growth level on a control sample $\left(F=\lg C_{t}-\right.$ $\left.\lg C_{0}\right)$;

$\lg C_{t}$ is the average decimal logarithm of the number of bacteria obtained from three samples for undergoing the analysis of the control cloth after an incubation of $24 \mathrm{~h}$

$\lg C_{0}$ is the average decimal logarithm of the number of bacteria obtained from the samples for testing the test cloth immediately after having infected.

$G$ is the growth level on a sample that has undergone antibacterial treatment $\left(\mathrm{G}=\lg \mathrm{T}_{\mathrm{t}}-\lg \mathrm{T}_{0}\right)$;

$\lg T_{t}$ is the average value of the decimal logarithm of the number of bacteria obtained from three samples for testing canvasses treated antibacterially after the incubation for 24 hours.

$\lg T_{0}$ is the average value of the decimal logarithm of the amount of bacteria obtained from three samples for testing pieces that have undergone antibacterial treatment immediately after the inoculation.

\section{Results}

\subsection{Composition, structure and morphology of NPs}

TEM images of the obtained nanoparticles are shown in Figure 2. It can be seen that the morphology and the size of the particles depend on the medium chosen for ablation. Zn_Air nanoparticles have a cubic and hexagonal plate form (close to spherical). The average size of nanoparticles obtained in air is about $20 \mathrm{~nm}$.

Elongated nanoparticles with the length of more than $100 \mathrm{~nm}$ are formed in water. Nanoparticles elongated in one direction with a length of more than $100 \mathrm{~nm}$ are formed in water. According to [20], nanorods are created by growing along the main direction [0001].

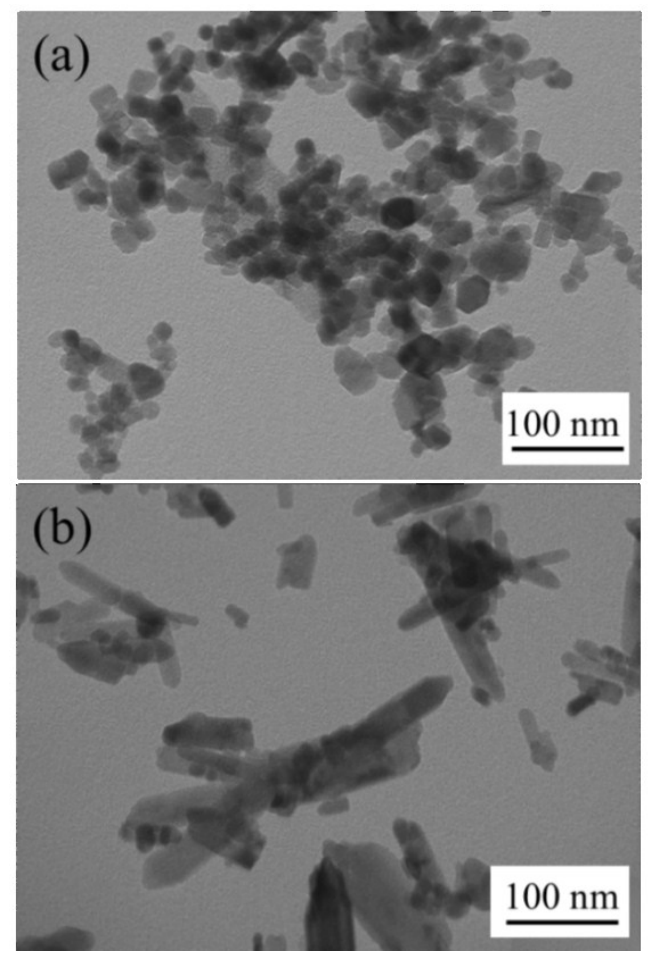

Fig. 2. TEM photographs of ZnO NPs obtained by PLA in air (a) and water (b).

The nanoparticle powders $\mathrm{Zn} \_$Air and $\mathrm{Zn} \_\mathrm{H}_{2} \mathrm{O}$ were investigated by the XRD method to determine the phase composition of the samples. The obtained diffractograms and PDF Cards of the expected phases are shown in Figure 3. The diffractograms show that the main crystalline phase of both powders is hexagonal zinc oxide of wurtzite type (186 space group, PDF Card \# 00036-1451). In addition, there are trace amounts of zinc metal with a hexagonal crystal lattice (196 space group, PDF Card \# 00-001-1244). The peak XRD at $2 \theta=43.19^{\circ}$ can be indexed to the $\mathrm{Zn}(100)$ diffraction plane. This peak is more intense for $\mathrm{Zn}$ Air than $\mathrm{Zn}_{-} \mathrm{H}_{2} \mathrm{O}$ because the saturation of water with oxygen leads to a stronger oxidation of nanoscales $\mathrm{Zn}$ to $\mathrm{ZnO}$. The sample $\mathrm{Zn}$ Air contains about $5-7 \%$ of the monoclinic phase of zinc hydroxynitrate (12 space group, PDF Card \# 00-024-1460). It is represented by the green line in Figure 2 and denoted as $\mathrm{ZHN}$ $\left(\mathrm{Zn}_{5}(\mathrm{OH})_{8}\left(\mathrm{NO}_{3}\right)_{2} \times 2 \mathrm{H}_{2} \mathrm{O}\right)$. It should be noted that conducting the synthesis in a flow reactor leads to less formation of zinc hydroxynitrate. Also, we noticed that air humidity played a big role in the formation of the $\mathrm{ZHN}$ phase.

It is known that metal hydroxide layered salts are formed as the result of the interaction of the transition metal oxide with the corresponding salt of this metal in the solid or liquid phase (for example, the interaction of solid zinc oxide in the presence of zinc nitrate and water forms zinc hydroxynitrate) [21]. We assume that the formation of $\mathrm{Zn}_{5}(\mathrm{OH})_{8}\left(\mathrm{NO}_{3}\right)_{2} \times 2 \mathrm{H}_{2} \mathrm{O}$ occurs in a similar way, but in our case, an important role is played by the 
formation of plasma during the synthesis. Nitrogen of air interacts with oxygen in the plasma in a humid environment to form $\mathrm{NO}_{3}^{-}$ions in a closed reactor.

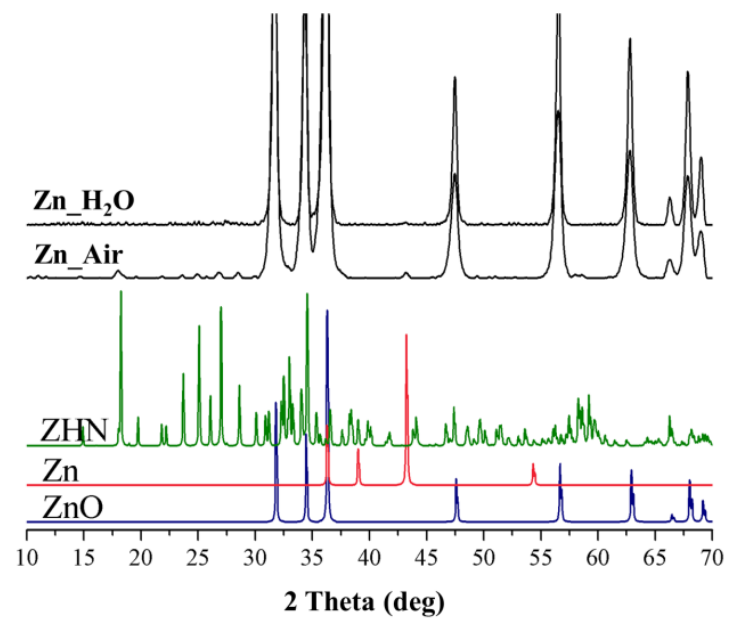

Fig. 3. XRD patterns of nanopowders obtained by PLA and PDF4 Cards.

\subsection{Structure and morphology of bandage materials models}

Materials of cotton fabric, filter paper and biodegradable polymeric scaffold from PLLA were investigated and modified with zinc oxide nanoparticles for modeling bandages with antibacterial properties. Cellulose is the main component of cotton and filter paper while biodegradable polymer consists of poly-1-lactide acid. SEM images of the primary (no modified) materials are presented in Figure 4. As can be seen from the figure the cotton consists of individual fibers with a diameter of 5 to $100 \mu \mathrm{m}$. They are woven into strands with a simple alternation directed perpendicularly. Fibers are distributed chaotically among filter paper and biodegradable polymer scaffolds. The fiber diameter of filter paper ranges from 7 to $150 \mu \mathrm{m}$. And the polymer's fibers have diameters from 0.8 to $2 \mu \mathrm{m}$.

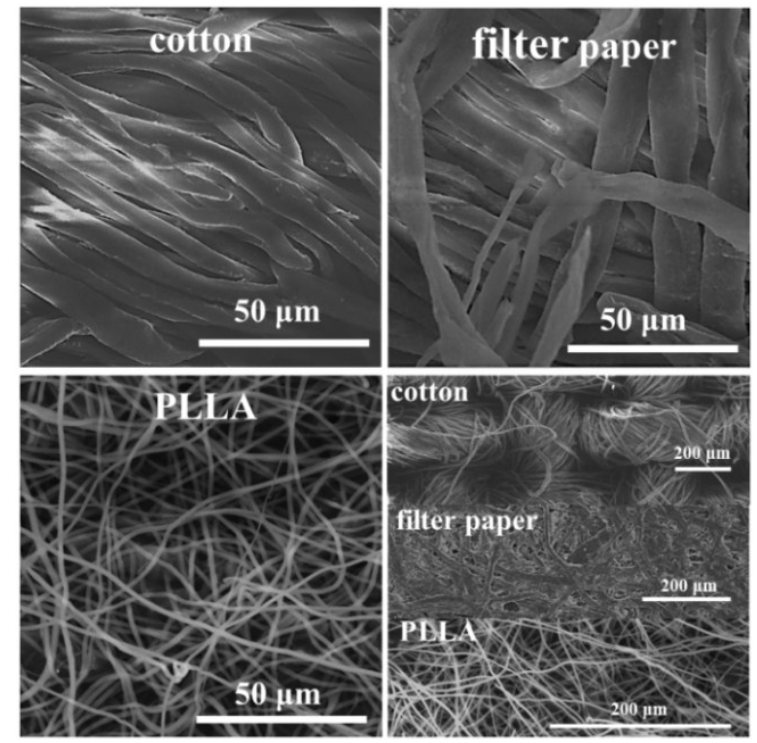

Fig. 4. SEM images of the no modified materials.
Also, the SEM study was carried out after the modification of the starting materials with $\mathrm{Zn}$ A Air and $\mathrm{Zn}_{-} \mathrm{H}_{2} \mathrm{O}$ nanoparticles. The results are depicted in Figure 5. It outlines that there are differences in the morphology of the modified materials. We can observe a large amount of $\mathrm{ZnO}$ nanoparticles with the form of individual particles and agglomerates on the surface.
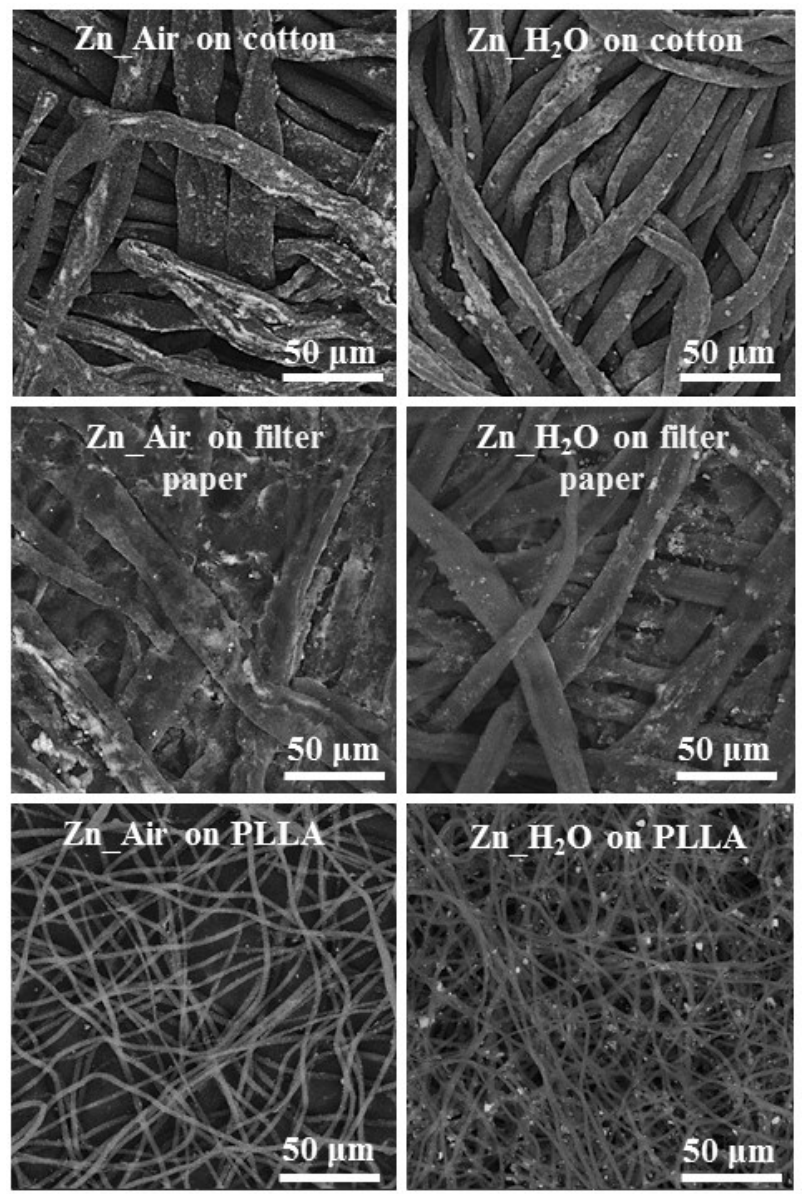

Fig. 5. SEM imaging of bandage model received on the BSE console.

However, large flakes and aggregates are observed on the SEM image after spreading $\mathrm{Zn}$ _Air nanoparticles on cotton and filter paper. If the particles are obtained in water by PLA, single agglomerates are observed, especially on the samples of PLLA. The reverse situation is observed nanoparticles deposited on the polymer.

Different heterogeneity of the coating can be related to the different dispersibility of the powder in water. First, the powders were dispersed in water and then applied to the materials. A Zn_Air powder was much better dispersed in water $(2.3 \mathrm{~g} / \mathrm{l})$, in contrast to the powder prepared in water $(1.6 \mathrm{~g} / 1)$.

Figure 6 shows the enlarged SEM images of cotton and biodegradable polymer scaffolds fibers coated with $\mathrm{Zn} \mathrm{H}_{2} \mathrm{O}$ nanoparticles. It can be seen that cotton and polymer are completely covered with $\mathrm{ZnO}$ nanoparticles. However, the distribution of particles over the surface is more uniform (the particles are more isolated) on the polymer. And, the particles are more aggregated on the cotton surface. 
The difference in the distribution of nanoparticles on the fibers of materials is associated with the presence of various groups on the surface. $-\mathrm{CH}_{2} \mathrm{OH}$ groups (on the bottom of Figure 6) can be present on the surface of the cotton. They have hydrophilic properties (the carbon atom is surrounded by two atoms of hydrogen and one $\mathrm{OH}$ group). Therefore, the zinc oxide particles are easily bound to the surface of the fabric through a hydrogen bond. Polymeric fibers on their surface have hydrophobic groups, for example, the bidentate $-\mathrm{CO}_{2}$ group (at the top of Figure 6).
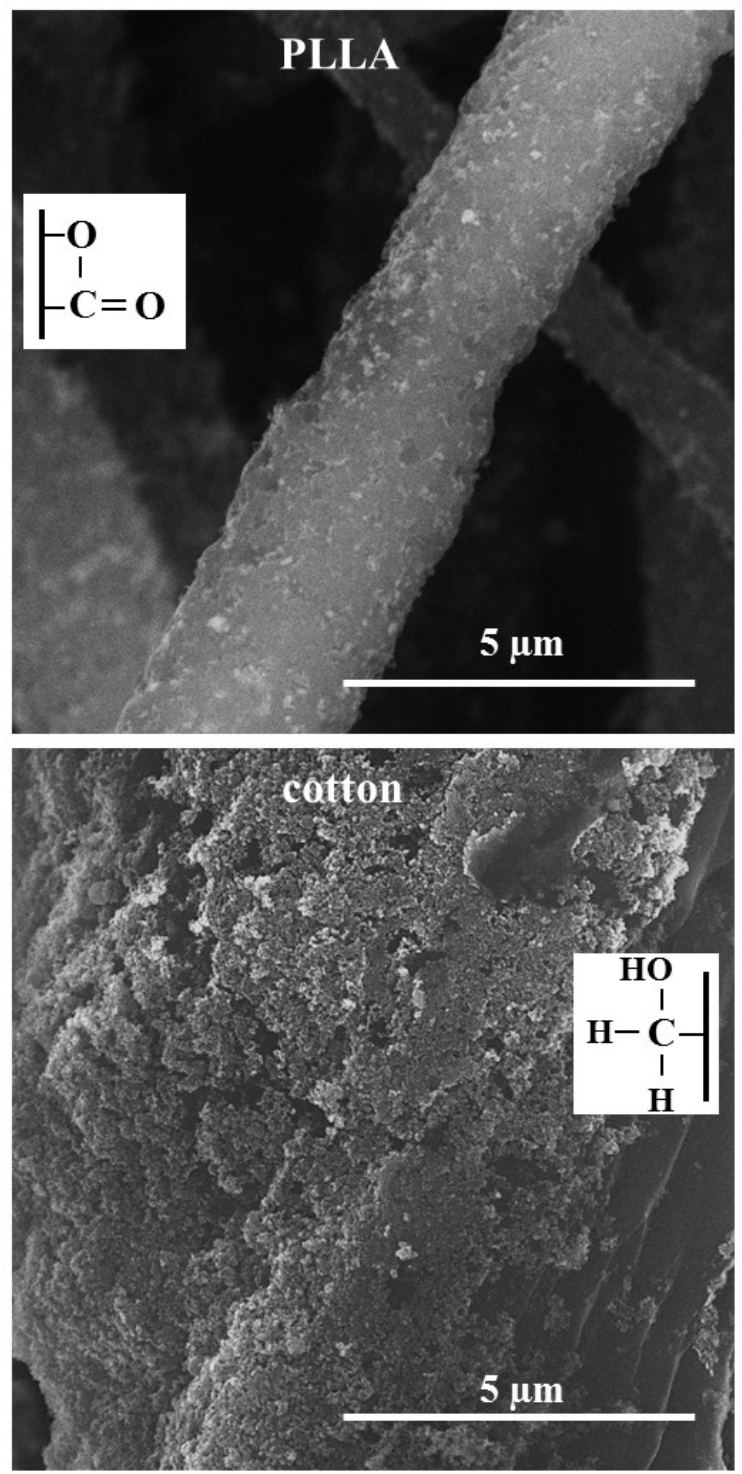

Fig. 6. SEM images of nanoparticles $\mathrm{Zn}_{-} \mathrm{H}_{2} \mathrm{O}$ deposited on polymer and fabric.

\subsection{Antibacterial activity of NPs and the model bandage materials}

A qualitative assessment of the antibacterial activity of nanoparticle powders was carried out by the method of the minimum bactericidal concentration. The results are presented in Table 1.

It was found that the inhibitory effect of $\mathrm{ZnO}$ nanoparticles produced by PLA in water is higher than of NPs obtained in air. The result related to the stability of nanoparticles in physiological solution. The compression of the double electric layer occurs differently when the nanoparticles are dispersed in $9 \%$ $\mathrm{NaCl}$. The compression of the double electric layer occurs less for the nanoparticles $\mathrm{Zn} \mathrm{H}_{2} \mathrm{O}$ and the colloidal solution is stable.

Table 1. Antibacterial activity of $\mathrm{ZnO}$ powders in solution.

\begin{tabular}{|c|c|c|c|}
\hline \multirow{2}{*}{ No. } & \multirow{2}{*}{$\mathrm{C}, \mathrm{g} / \mathrm{l}$} & \multicolumn{2}{|c|}{ Sample } \\
\hline & & Zn_Air & $\mathrm{Zn} \_\mathrm{H}_{2} \mathrm{O}$ \\
\hline 1 & 0.001 & + & + \\
\hline 2 & 0.01 & + & - \\
\hline 3 & 0.1 & + & - \\
\hline 4 & 1 & - & - \\
\hline 5 & 10 & - & - \\
\hline
\end{tabular}

Typically, the antibacterial activity of textile materials is evaluated by the diffusion method in agar, but this is not suitable for the various types of materials we used. The most sensitive method is to determine the antibacterial activity of products with antibacterial treatment in accordance with ISO 20743:2013. In this method, the bacterial suspensions are inoculated directly onto the tissue. Its antibacterial activity is quantitated by the difference in the number of bacteria in the control and test samples immediately after inoculation and after $24 \mathrm{~h}$ incubation. The results of this test are presented in Table 2 .

The finishing treatment is considered as active if the value $A>3$, according to [18]. The table 2 shows that the values of antibacterial activity are maximal in this experiment. We did not observe the growth of bacteria or the presence of isolated colonies in Petri dishes.

Table 2. Antibacterial activity the model bandage materials.

\begin{tabular}{|c|c|c|c|}
\hline \multirow[b]{2}{*}{ Sample } & \multicolumn{2}{|c|}{ The level of growth } & \multirow{2}{*}{$\begin{array}{c}\text { Antibacterial } \\
\text { activity } \\
(\mathbf{A}=\mathbf{F}-\mathbf{G})\end{array}$} \\
\hline & $\begin{array}{c}\text { Control } \\
F=\underset{\lg C_{t}-}{\lg C_{0}}\end{array}$ & $\begin{array}{c}\text { Sample } \\
G=\lg T_{t}- \\
\lg T_{0}\end{array}$ & \\
\hline$\underset{\text { cotton }}{\mathrm{Zn}_{2} \mathrm{H}_{2} \mathrm{O} /}$ & \multirow{2}{*}{-0.438} & -3.798 & 3.360 \\
\hline $\begin{array}{c}\text { Zn_Air / } \\
\text { cotton }\end{array}$ & & -3.958 & 3.520 \\
\hline $\begin{array}{c}\mathrm{Zn}_{\overline{-} \mathrm{H}_{2} \mathrm{O} /} \\
\text { filter } \\
\text { paper } \\
\end{array}$ & \multirow{2}{*}{-0.104} & -4.362 & 4.258 \\
\hline $\begin{array}{l}\text { Zn_Air / } \\
\text { filter } \\
\text { paper }\end{array}$ & & -4.367 & 4.263 \\
\hline $\begin{array}{l}\mathrm{Zn \_ H_{2 } \mathrm { O } /} \\
\text { polymer }\end{array}$ & \multirow{2}{*}{-0.474} & -4.491 & 4.017 \\
\hline $\begin{array}{l}\text { Zn_Air / } \\
\text { polymer }\end{array}$ & & -4.496 & 4.022 \\
\hline
\end{tabular}


The results were slightly worse for samples on cotton fabric, which is explained by higher adhesion of nanoparticles on the surface of cotton.

The obtained $A$ value of our materials for S.aureus is higher than for commercial antibacterial dispersions according to $[22,23]$. Both experiments showed high antibacterial activity against S.aureus (ATCC 25923) of NPs $\mathrm{ZnO}$ obtained by both methods.

\section{Conclusions}

Nanopowders obtained by pulsed laser ablation of a zinc target in water and air are compared in this paper. It is demonstrated that the composition and structure of the received $\mathrm{ZnO}$ nanoparticles depend on the conditions of the PLA process. The antibacterial activity of the obtained powders against a gram-positive bacterial strain (S.aureus ATCC 25923) was studied. It was found that the minimum bactericidal concentration for the powder prepared in the air was higher $(1 \mathrm{~g} / \mathrm{l})$ than for the powder prepared in water $(0.01 \mathrm{~g} / 1)$.

The model materials for the antibacterial bandage were made of cotton, filter paper and biodegradable polymer scaffolds (poly-l-lactide acid) and coated with the obtained nanoparticles. High antibacterial activity against S.aureus was detected by treating the materials with nanoparticles obtained by pulsed laser ablation of zinc in the medium of air or water.

\section{Acknowledgments}

The study was supported by the scholarship program of the President of the Russian Federation for young scientists and post-graduate students (SP-1772.2018.4). The authors thank V.O. Trufanov for English review.

\section{References}

1. Purulent infection, Big Medical Encyclopedia, available http://bigmed.info/index.php/PURULENT_INFECTI $\mathrm{ON}$

2. L.S. Naira, C.T. Laurencin, Prog. Polym. Sci. 32, 762 (2007)

3. G.D. Mogosanu, A.M. Grumezescu, Int. J. Pharm. 463, 127 (2014)

4. A.J. Huh, Y.J. Kwon, J. Controlled Release 156, 128 (2011)

5. L. Wang, C. Hu, L. Shao Int. J. Nanomedicine. 12, 1227 (2017)

6. J. Jiang, J. Pi, J. Cai, Bioinorg Chem Appl. 2018, 1062562 (2018)

7. G.V Vimbela, S.M. Ngo, C. Fraze, L. Yang, D.A. Stout, Int. J. Nanomedicine. 12, 3941 (2017)

8. J. Milenkovic, J. Hrenovic, D. Matijasevic, M. Niksic, N. Rajic, Environ. Sci. Pollut. Res. 24, 20273 (2017)
9. M.C. Sportelli, R.A. Picca, N. Cioffi, Trends in Analytical Chemistry 84, 131 (2016)

10. P.J.P. Espitia, N. de F.F. Soares, J.S. dos R. Coimbra, N.J. de Andrade, R.S. Cruz, E.A.A. Medeiros, Food Bioprocess Technol. 5, 1447 (2012)

11. G. Colon, B.C. Ward, T.J. Webster, J. Biomed. Mater. Res. Part A 78A, 595 (2006)

12. A. Sirelkhatim, S. Mahmud, A. Seeni, N.H.M. Kaus, L.C. Ann, S.K.M. Bakhori, H. Hasan, D. Mohamad, Nano-Micro Lett 7, 219 (2015)

13. D. Raoufi, Renew. Energy 50, 932 (2013)

14. J. Wojnarowicz, R. Mukhovskyi, E. Pietrzykowska, S. Kusnieruk, J. Mizeracki, W. Lojkowski, Beilstein J. Nanotechnol. 7, 721 (2016)

15. D. Zhang, B. Gökce, S. Barcikowski. Chem. Rev. 117, 3990 (2017)

16. J.-N. Janice Low, W. Wong, W. Rashmi, A. Kadhum, A.B. Mohamad, J. of Eng. Sci. Technol. 12(2), 29 (2017)

17. V. Svetlichnyi, A. Shabalina, I. Lapin, D. Goncharova, A. Nemoykina, Appl. Surf. Sci. 372, 20 (2016)

18. A.D. Badaraev, A.L. Nemoykina, E.N. Bolbasov, S.I. Tverdokhlebov, Resour. Technol. 3, 204 (2017)

19. ISO 20743:2013 Textiles - Determination of antibacterial activity of textile products (2nd Edition, 2013)

20. Y.V. Kaneti, Z. Zhang, J. Yue, Q.M.D. Zakaria, C. Chen, X. Jiang, A. Yu, Phys. Chem. Chem. Phys. 16, 11471 (2014)

21. A. Moezzi, Zinc oxide:new insights into a material for all ages, $\mathrm{PhD}$ thesis (University of Technology Sydney, 2012)

22. E.K. Karanikas, N.F. Nikolaidis, E.G. Tsatsaroni Prog. Org. Coat. 76, 1112 (2013)

23. F. Ferrero, M. Periolatto, S. Ferrario J. Clean. Product. 96, 244 (2015) 